\title{
A Self-Adaptive Selection Weighting Method of Multiple Attribute Group Decision Making
}

\author{
Xiaobo Bai* \\ School of Management \\ Xi'an Polytechnic University \\ Xi'an, China \\ baixiaobo@xpu.edu.cn \\ Zheng He \\ School of Management \\ Xi'an Polytechnic University \\ Xi'an, China \\ heezheng_128877@163.com
}

\author{
Jiangang Tian \\ Department of Engineering Basis \\ Xi'an Border and Costal Defence Academy \\ Xi'an, China \\ tianjiangang@163.com
}

\author{
Jingfeng Shao \\ School of Management \\ Xi'an Polytechnic University \\ Xi'an, China \\ shaojingfeng1980@aliyun.com
}

\begin{abstract}
To solve the problem of the difficulty for selecting many weighting methods in multiple attribute group decision making, the correlation between subjective and objective weighted vector conflict factor and the assessment result accuracy was analyzed, and then, an adaptive selection algorithm based on conflict threshold was proposed. As verified by the simulation, the results show that the algorithm eliminates the effect on subjective and objective weighted vector conflict to the evaluation result, improves the calculation accuracy, and realizes the self adaptive selection based on conflict threshold. Moreover, when the conflict factor is less than the threshold, adaptive selection algorithm will choose time complexity been lower than integrated weighting method of the multiplicative synthesis principle. On the contrary, when the conflict factor is greater than the threshold, it will choose the combination weighted method of high calculation result accuracy based on game theory.
\end{abstract}

Keywords-Conflict factor; The weighted vector; Adaptive; Threshold; Multi attribute group decision making

\section{INTRODUCTION}

The core problem of multi attribute decision making is weighting method of index. Different weighting method could get the different weight. In current research state, there are three weighting methods, namely subjective weighting method, objective weighting method and comprehensive weighting method.

Subjective weighting method means that index weight is given by the degree of experts attention. The main methods are Delphi method[1], binomial coefficient method[2,3], Decision Alternative Ratia Evaluation (DARE)[4], and et al. The shortcoming of these methods are rely on the decision expert's knowledge, experience and personal preference. Therefore, the index weighting method of AHP was improved by MA Yundong[5], the basic idea is that mean value of the index weighting of multi experts is as the final weighting. Due to the fuzzy in the weighting procedure, the Maximum Characteristic Root Method (MCRM) was extended to fuzzy form by James J. Buckley[6], and to confirm fuzzy weighting of every index. The fuzzy AHP method was utilized for weighting to indexes based on Trigonometric Fuzzy Number in $[7,8]$. But in the weighting and decision making procedure, the inner relation of index cannot be completely distinguished by personal subjective consciousness.

In consideration of the problem and shortcoming of subjective weighting. The objective weighting methods were proposed by lots of scholars. Weighting method of index is from the inner relation of index, so then, objective of index weighting is ensured. And, it has a strong theoretical basis for mathematics $[9,10]$. The methods, as follows entropy weight, maximal deviation and math programming method, et al in [11], based on fuzzy multi attribute decision making of the Choquet fuzzy integral, the complexity index weighting method was proposed. In [12], to calculate fuzzy measure, the unsupervised system identification method was proposed. But, objective weighting method, which is lack of universality, and rely on the actual business area, and the subjective preference and experience of decisive person cannot be presented, and the calculation method is more complexity.

To solve the shortcoming of subjective weighting and objective weighting. The comprehensive weighting methods were proposed based on combing subjective weight and objective weight by lots of scholars. So then, the knowledge and experience of experts are presented, and the inner relation information of indexes is denoted too. As in [13-19], the comprehensive weighting methods are based on multiplication and addition, sum of squares of deviations and fuzzy entropy weight.

According to the literature review, in the multi attribute decision making area, index weighting methods were analyzed and researched, and got lots of results from different view of lots of scholars. But, the existence of subjective and objective weighting is contrary to human intuition, and there is a great difference between the evaluation result and the expected value. Because the source of the index weighting of subjective and objective is different. Comprehensive weighting method can obtain more accurate evaluation result, But comprehensive 
weighting is based on subjective and objective weighting, and comprehensive weighting need lots of calculation, as matrix operation, solving linear algebraic equations, et al, which make the calculation of evaluation procedure is more bigger, so that we cannot chose a suite method in practical application. Therefore, this paper defined conflict of subjective and objective index vector in mathematical language, firstly. And then, the influence of evaluation result under the conflict was analyzed. Finally, the calculation efficiency and performance of four main weighting methods were researched under different conflict factor, and a self suitable index weighting method, which can promote calculation efficiency and accuracy of evaluation result, was proposed by conflict threshold value.

\section{Four WeIghting Methods}

\section{A. Index Weighting Method of AHP}

The basic idea of analytic hierarchy process(AHP) is that alternatives are decomposed different hierarchy structure, and then, a character vector of the judgment matrix is solved, and solve the priority weight of every hierarchy elements which are relative to up hierarchy element. Finally, the weighted sum method is used to merge the final weight of the alternatives to the total target. The detail procedure is in [2].

\section{B. Entropy Weight of Index}

Entropy Weight(EW) is objective weighting method of index. The calculation method is denoted as.

$$
h_{b}=\frac{1-C_{b}}{n-\sum_{b=1}^{n} C_{b}}, \quad b=1,2, \ldots, n
$$

Where $h_{b}$ is entropy weight of index $b, C_{b}$ is entropy value of index $b$, the calculation method is in the [14], $n$ is the number of index.

\section{Multiplicative Synthesis and Normalization \\ Comprehensive Weighting}

To overcome the knowledge experience of judging experts in subjective empowerment, the defect of poor consistency and low accuracy of index weight and the loss of important value in subjective evaluation caused by objective empowerment method[15]. Multiplicative synthesis and normalization principle was used to design a comprehensive weighting method by researcher. That is as follows.

$$
W_{i}=\frac{W_{s}^{i} \times W_{o}^{i}}{\sum_{i=1}^{n} W_{s}^{i} \times W_{o}^{i}} \quad i=1,2, \ldots, \mathrm{n}
$$

Where $W_{i}$ denoted comprehensive weight of the i-th index, $W_{s}^{i}$ is the subjective weight of the $\mathrm{i}$-th index. $W_{o}^{i}$ is the objective weight of the i-th index.

\section{Comprehensive weighting Based on Game theory}

The comprehensive weighting method based on game theory, the principle is that calculate a comprehensive weighting vector after the subjective and objective weights are ensured, which has the deviation minimization between subjective weighting vector and objective weighting vector. So that the information of subjective weight and objective weight of the index can be retained[17,18]. The calculation method is as follows.

$$
W_{c}=\sum_{i=1}^{m} \alpha_{i} W_{i}^{T}, \alpha_{i}>0
$$

Where $W_{i}^{T}$ is weight vector, then, the procedure of calculating $W_{c}$ can be considered as optimization of linear combination coefficients for (3).The aim is to make the deviation minimization of $W_{c}$ to $W_{i}^{T}$. The detail calculation procedure of $\alpha_{i}$ is in [18].

\section{E. Conflict Factor of Subjective and Objective Weight Vectors}

For the procedure of index weighting, the conflict is existing between subjective weight of AHP and objective weight of entropy weighting. The results are contrary for human intuition. For this, Firstly, we defined the conflict degree of subjective weight vector and objective weight vector with mathematical language. The conflict degree was presented as follows.

$$
W_{s}=\left(w_{s_{1}}, w_{s_{2}}, \ldots, w_{s_{n}}\right),\left(0 \leq w_{s_{i}} \leq 1, \sum_{i=1}^{n} w_{s_{i}}=1\right) \quad \text { is } \quad \text { The }
$$

subjective weight vector of hierarchy weighting method of AHP, $\quad W_{o}=\left(w_{o_{1}}, w_{o_{2}}, \ldots, w_{o_{n}}\right),\left(0 \leq w_{o_{i}} \leq 1, \sum_{i=1}^{n} w_{o_{i}}=1\right)$ is the objective weight vector of entropy weighting method. And then, the conflict factor of two weight vectors is denoted with Euclidean distance. The equation is as follows.

$$
k=\sqrt{\sum_{i=1}^{n}\left(W_{s i}-W_{o i}\right)^{2}},(0 \leq k \leq 1)
$$

If the $k$ is closer to 0 , then the result illustrates the conflict of subjective and objective weight vector is little. Else if the $k$ is closer to 1 , the result illustrates the conflict of subjective and objective weight vector is big.

\section{CASe Analysis of Four Weighting Methods}

\section{A. Calculation Case 1}

To illustrate the conflict factor of subjective and objective weight vector, and the time complexity of the different weighting algorithm. Firstly, based on assets management evaluation system of high school of the [20], and expended it. As follows, the conversion rate of scientific research 
achievements, the proportion of scientific research projects above the provincial level and et al were added to scientific research achievement criterion level. And then, evaluation group, which was composed of 5 people, as follows. Computer technician and director of department of university, and backbone of scientific research and teaching, was built. After the evaluation group known and analyzed the current assets management state of the university $T$. The assets management performance of university $T$ was evaluated, the procedure of which is as follows.

(1) The Delphi survey method was used. According to relative weight of index, the judgment matrix was built. If consistency of judgment matrix is satisfied, then subjective weight and objective of 25 indexes were calculated with weighting method of AHP and entropy weighting method. And then, the two comprehensive weight vectors were obtained with (2) and (3). For convenience, the weight vector were recorded as $W_{s}, W_{o}, W_{a m}, W_{g m}$, respectively. The evaluation results were shown in Table I.

(2) The evaluation group evaluated the sore of assets management of university $T$. The score vectors are, $s v_{1}, s v_{2}, s v_{3}, s v_{4}$ and $s v_{5}$, respectively. The standard of evaluation is shown in Table II.

table I. Index Weight And Evaluation Result( $V$ ) Of Four Weighting Methods Of Case 1

\begin{tabular}{|c|c|c|c|c|c|c|c|c|c|}
\hline Indexes & $\begin{array}{c}\text { Subjective } \\
\text { weight of } \\
\text { AHP }\end{array}$ & $\begin{array}{c}\text { Objective } \\
\text { weight of } \\
\text { entropy }\end{array}$ & $\begin{array}{c}\text { Comprehen } \\
\text { sive weight } \\
\text { of (2) }\end{array}$ & $\begin{array}{c}\text { Comprehen } \\
\text { sive weight } \\
\text { of (3) }\end{array}$ & Indexes & $\begin{array}{c}\text { Subjectiv } \\
\text { e weight } \\
\text { of AHP }\end{array}$ & $\begin{array}{c}\text { Objectiv } \\
\text { e weight } \\
\text { of } \\
\text { entropy }\end{array}$ & $\begin{array}{c}\text { Comprehens } \\
\text { ive weight of } \\
\text { (2) }\end{array}$ & $\begin{array}{l}\text { Comprehensi } \\
\text { ve weight of } \\
\text { (3) }\end{array}$ \\
\hline $\mathrm{C}_{1}$ & 0.035 & 0.016 & 0.016 & 0.022 & $\mathrm{C}_{14}$ & 0.026 & 0.037 & 0.009 & 0.032 \\
\hline $\mathrm{C}_{2}$ & 0.028 & 0.069 & 0.054 & 0.055 & $\mathrm{C}_{15}$ & 0.022 & 0.166 & 0.025 & 0.058 \\
\hline $\mathrm{C}_{3}$ & 0.034 & 0.195 & 0.189 & 0.143 & $\mathrm{C}_{16}$ & 0.030 & 0.031 & 0.047 & 0.014 \\
\hline $\mathrm{C}_{4}$ & 0.037 & 0.022 & 0.023 & 0.027 & $\mathrm{C}_{17}$ & 0.042 & 0.035 & 0.006 & 0.015 \\
\hline $\mathrm{C}_{5}$ & 0.041 & 0.078 & 0.091 & 0.066 & $\mathrm{C}_{18}$ & 0.046 & 0.020 & 0.003 & 0.028 \\
\hline $\mathrm{C}_{6}$ & 0.042 & 0.011 & 0.013 & 0.021 & $\mathrm{C}_{19}$ & 0.023 & 0.092 & 0.024 & 0.010 \\
\hline $\mathrm{C}_{7}$ & 0.010 & 0.037 & 0.010 & 0.028 & $\mathrm{C}_{20}$ & 0.024 & 0.017 & 0.003 & 0.017 \\
\hline $\mathrm{C}_{8}$ & 0.050 & 0.169 & 0.240 & 0.131 & $\mathrm{C}_{21}$ & 0.045 & 0.008 & 0.010 & 0.040 \\
\hline $\mathrm{C}_{9}$ & 0.038 & 0.026 & 0.029 & 0.030 & $\mathrm{C}_{22}$ & 0.016 & 0.049 & 0.048 & 0.075 \\
\hline $\mathrm{C}_{10}$ & 0.019 & 0.017 & 0.009 & 0.018 & $\mathrm{C}_{23}$ & 0.071 & 0.034 & 0.047 & 0.027 \\
\hline $\mathrm{C}_{11}$ & 0.034 & 0.020 & 0.019 & 0.025 & $\mathrm{C}_{24}$ & 0.098 & 0.025 & 0.013 & 0.040 \\
\hline $\mathrm{C}_{12}$ & 0.026 & 0.006 & 0.004 & 0.012 & $\mathrm{C}_{25}$ & 0.096 & 0.009 & 0.035 & 0.039 \\
\hline $\mathrm{C}_{13}$ & 0.066 & 0.005 & 0.016 & 0.022 & $V$ & 62.98 & 63.55 & 63.12 & 63.40 \\
\hline
\end{tabular}

TABLE II. EVALUATION STANDARD OF AsSETS MANAGEMENT ACHIEVEMENTS OF HIGH SCHOOL

\begin{tabular}{|l|l|l|}
\hline \multicolumn{1}{|c|}{ id } & \multicolumn{1}{|c|}{ Evaluation rank } & \multicolumn{1}{c|}{ Score } \\
\hline 1 & Excellent & $>90$ \\
\hline 2 & Good & $80 \sim 90$ \\
\hline 3 & Secondary & $70 \sim 80$ \\
\hline 4 & Pass & $60 \sim 70$ \\
\hline 5 & Fail & $<60$ \\
\hline
\end{tabular}

(3) To reduce the score preference, which due to knowledge and experience of experts. We calculated the average value of five score vectors of step 2 . The calculation method is denoted as follows.

$$
\overline{s v}=\frac{1}{n}\left(s V_{1}+s V_{2}+\ldots .+s V_{n}\right)
$$

(4) To show the comprehensive evaluation efficiency. The preference(v) was calculated in (6).

$$
V=\sum_{i=1}^{m} w_{i} \times \overline{S V_{i}}
$$

Then, five evaluation experts calculated the evaluation score vectors, which are as follows.

$S V_{1}=(60.64,54.28,70.39,79.56,74.55,89.29,31.93,72.66$, $78.85,51.17,63.13,69.78,36.37,53.14,52.02,44.98,58.89$, $64.26,60.11,55.09,61.48,58.47,81.93,79.45,53.98)^{T}$

$s V_{2}=(53.84,50.48,63.29,80.75,74.97,56.35,31.17,54.74$ $67.46,54.23,50.70,58.98,52.09,53.19,69.25,34.64,65.72$, $61.02,59.84,54.39,56.59,61.21,72.65,72.13,67.03)^{T}$

$S V_{3}=(56.99,52.68,65.82,71.08,80.23,85.33,39.31,73.00$ $80.31,50.72,58.63,42.19,59.24,56.80,52.42,43.37,58.86$, $70.27,61.17,66.00,55.06,58.07,78.57,60.76,73.41)^{T}$

$S V_{4}=(70.99,51.24,56.32,79.73,76.81,93.47,55.05,63.96$, 66.16,52.18,60.23,35.22,59.67,61.67,59.54,51.05,60.84, $45.04,76.60,66.84,65.13,60.38,79.76,56.04,73.80)^{T}$

$S V_{5}=(65.11,52.26,82.15,75.73,74.26,85.56,59.49,47.84$, 88.49,64.58,61.77,35.87,27.32,55.00,55.14,42.05,54.07, $64.07,73.67,73.50,69.73,70.49,80.91,56.48,46.89)^{T}$

Then, calculated the average vector of five evaluation experts with (5).

\footnotetext{
$\overline{S v}=(61.51,52.19,67.59,77.37,76.16,82.00,43.39,62.44$, $76.26,54.58,58.89,48.41,46.94,55.96,57.67,43.22,59.68$, $60.93,66.28,63.16,61.60,61.72,78.76,64.97,63.02)^{T}$
} 
The conflict factor $k=0.284$, which was calculated with (4). And then , $\overline{s v}$, subjective weight vector $\left(W_{s}\right)$ of AHP, objective weight vector $\left(W_{o}\right)$ of entropy weighting, and two comprehensive weight vectors $\left(W_{a m}, W_{g m}\right)$ were used to calculate the performance value, which were as $V_{s}^{1}=62.98, V_{o}^{1}=63.55, V_{a c}^{1}=63.12$ and $V_{g c}^{1}=63.40$, respectively.

The analysis of the results. $V_{s}^{1} 、 V_{o}^{1} 、 V_{a c}^{1}$ and $V_{g c}^{1}$ were as four times independently test to each other. The expect value was $E(V)=63.26$, variance was $D(V)=0.0481$. Therefore, the four evaluation results deviate from the expected value $E(V)$ very little, and the deviation of $V_{g c}^{1}$ with $E(V)$, which equal 0.114 , was the least, The absolute difference is 0.569 , which was $V_{s}^{1}$ with $V_{o}^{1}$. This results illustrate that when $\mathrm{k}=0.284$, we can obtain the satisfactory evaluation result, and which is satisfactory evaluation accuracy, with subjective weighting of AHP, objective weight of entropy weighting, (2) and (3). But, the result is the closest to expect value with comprehensive weighting method based on game theory.

\section{B. Calculation Case 2}

To further illustrate influence of conflict factor changes to evaluation accuracy. Based on indexes of calculation case 1 , weighting method of AHP, entropy weighting method, and two comprehensive weighting methods were used to weight to the indexes, the weight vectors are shown in Table III. In this calculation case, the conflict factor $(k)$ equal 0.508 , based on the average score vector of indexes of calculation case 1, and weight vectors which are shown in Table III, were used to calculate the evaluation results with (6). The results are $V_{s}^{2}=70.23, V_{o}^{2}=63.23, V_{a c}^{2}=68.83$ and $V_{g c}^{2}=66.80$, respectively.

The analysis of the results. $V_{s}^{2} 、 V_{o}^{2} 、 V_{a c}^{2}$ and $V_{g c}^{2}$ are the results of four times independency tests, which expect value $E(V)$ equal 67.27, variance $D(V)$ equal 6.94. As a whole, the deviation is bigger between the four evaluation results and expect value $(E(\mathrm{~V}))$, but the deviation of $V_{g c}^{2}$ is the least, which is 0.473 , while, the absolute difference of $V_{s}^{2}$ with $V_{o}^{2}$ is 7.00 . These results show that when conflict factor $(\mathrm{k}=0.508)$, if directly use weighting method of AHP or entropy weighting method, the deviations of evaluation results with expect value $(E(V))$ are bigger. But, the deviation of the results of the two comprehensive weighting method is less. Therefore, according to the same results of calculation case 1 and case 2 , the conclusion is that the evaluation results based on game theory weighting method, is closer to the expect value than subjective or objective weighting method.

TABLE III. IndeX Weight And Evaluation Result(V) Of Four Weighting Methods Of CASE 2

\begin{tabular}{|c|c|c|c|c|c|c|c|c|c|}
\hline Indexes & $\begin{array}{c}\text { Subjective } \\
\text { weight of } \\
\text { AHP } \\
\end{array}$ & $\begin{array}{c}\text { Objective } \\
\text { weight of } \\
\text { entropy } \\
\end{array}$ & $\begin{array}{c}\text { Comprehensi } \\
\text { ve weight of } \\
\text { (2) } \\
\end{array}$ & $\begin{array}{c}\text { Comprehensi } \\
\text { ve weight of } \\
\text { (3) } \\
\end{array}$ & Indexes & $\begin{array}{c}\text { Subjective } \\
\text { weight of } \\
\text { AHP } \\
\end{array}$ & $\begin{array}{c}\text { Objective } \\
\text { weight of } \\
\text { entropy }\end{array}$ & $\begin{array}{c}\text { Comprehensi } \\
\text { ve weight of } \\
\text { (2) } \\
\end{array}$ & $\begin{array}{c}\text { Comprehens } \\
\text { ive weight of } \\
(3) \\
\end{array}$ \\
\hline $\mathrm{C} 1$ & 0.040 & 0.011 & 0.021 & 0.026 & $\mathrm{C} 14$ & 0.006 & 0.034 & 0.009 & 0.020 \\
\hline $\mathrm{C} 2$ & 0.041 & 0.019 & 0.035 & 0.030 & $\mathrm{C} 15$ & 0.007 & 0.075 & 0.024 & 0.040 \\
\hline C3 & 0.012 & 0.295 & 0.163 & 0.150 & $\mathrm{C} 16$ & 0.008 & 0.003 & 0.001 & 0.005 \\
\hline C5 & 0.401 & 0.021 & 0.385 & 0.215 & $\mathrm{C} 18$ & 0.001 & 0.019 & 0.001 & 0.010 \\
\hline C6 & 0.046 & 0.011 & 0.024 & 0.029 & C19 & 0.080 & 0.004 & 0.016 & 0.043 \\
\hline C7 & 0.006 & 0.037 & 0.010 & 0.021 & $\mathrm{C} 20$ & 0.062 & 0.024 & 0.069 & 0.044 \\
\hline $\mathrm{C} 8$ & 0.009 & 0.180 & 0.074 & 0.093 & C21 & 0.003 & 0.043 & 0.006 & 0.023 \\
\hline $\mathrm{C} 10$ & 0.030 & 0.007 & 0.010 & 0.019 & $\mathrm{C} 23$ & 0.126 & 0.002 & 0.010 & 0.065 \\
\hline C11 & 0.010 & 0.020 & 0.009 & 0.015 & $\mathrm{C} 24$ & 0.001 & 0.003 & 0.001 & 0.002 \\
\hline $\mathrm{C} 12$ & 0.023 & 0.007 & 0.007 & 0.015 & $\mathrm{C} 25$ & 0.002 & 0.022 & 0.002 & 0.012 \\
\hline $\mathrm{C} 13$ & 0.020 & 0.009 & 0.008 & 0.015 & $V$ & 70.23 & 63.23 & 68.83 & 66.80 \\
\hline
\end{tabular}

\section{Analysis of Conflict factor an Absolute Difference}

To more perfectly illustrate the relevance of the conflict factor of subjective and objective weight vectors with the absolute difference of the evaluation results which are based on subjective weight vector and objective weight vector. And when the conflict factor is increased, degree of deviation of evaluation results which were calculated with four weighting methods with expect value. So, we do 18 times weighting and evaluation calculation, and the generation data was analyzed, and then, the analysis result is shown in Fig. 1.

In Fig. 1, $\left|V_{\mathrm{s}}-V_{\mathrm{o}}\right|$ denotes absolute difference, which is calculated by subjective weight of AHP and entropy weight. $\left|V_{s}-E(V)\right|$ denotes the absolute difference which is 
between the evaluation result of subjective weight of AHP and expect value $(\mathrm{E}(\mathrm{V})) .\left|V_{\mathrm{o}}-E(V)\right|$ denotes absolute difference which is between the evaluation result of entropy weighting and expect value $(\mathrm{E}(\mathrm{V}))$. $\left|V_{a c}-E(V)\right|$ denotes that absolute difference is between the evaluation result of comprehensive weighting method of based on multiplicative normalization principle and expect value. $\left|V_{g c}-E(V)\right|$ denotes that absolute difference is between the evaluation result of based on comprehensive weighting method of game theory and expect value.

According to analyzing the change procedure of five curies, in Fig 1. We can get the conclusion, which are as follows.

(1) The change procedure of $\left|V_{\mathrm{s}}-V_{\mathrm{o}}\right|$ shows that the relation of between absolute difference and conflict factor is positive correlation. To quantitatively denote the correlation coefficient of the both with the (7) [21].

$$
R(i, j)=\frac{C(i, j)}{(C(i, i) C(j, j))^{1 / 2}}
$$

Where $i$ and $j$ denote the $i$-th and $j$-th column vector. $C=\operatorname{cov}(i, j)$.

According to calculation, shows that the correlation coefficient of between and absolute difference and conflict factor is 0.965 . This result illustrates the both are high correlation, and further illustrate influence of conflict factor value to $\left|V_{\mathrm{s}}-V_{\mathrm{o}}\right|$.

(2) When conflict factor $k<=0.337$, use the one of the four weighting methods in this paper, both could obtain the relative accuracy evaluation result. Because the results shows that if use the weights, which are ensured by four weighting methods in this paper, the absolute difference of between all of the results and expect value $(\mathrm{E}(\mathrm{V}))$ are less than 0.3 . That are $\left|V_{\mathrm{s}}-E(V)\right|<0.3,\left|V_{\mathrm{o}}-E(V)\right|<0.3, \quad\left|V_{a c}-E(V)\right|<0.3$, and $\left|V_{g c}-E(V)\right|<0.3$.

(3) When conflict factor $k>0.337$. Firstly, the correlation coefficient of between evaluation value of based on game theory comprehensive weighting and evaluation value of based on subjective and objective weighting methods is the most least. So, evaluation value based on comprehensive weighting of (3), is obviously superior to other weighting methods, and is the most consistent. Secondly, the result of comprehensive weighting method based on the principle of multiplication and normalization is better than others. If the conflict factor is increased constantly. $\left|V_{\mathrm{s}}-E(V)\right|,\left|V_{\mathrm{o}}-E(V)\right|,\left|V_{a c}-E(V)\right|$ and $\left|V_{g c}-E(V)\right|$ are increased too. It present that the three are bigger correlation with subjective and objective weight vectors. But, in comparison, the increasing procedure of $\left|V_{g c}-E(V)\right|$ is the most slowly, and $\min \left(\left|V_{g c}-E(V)\right|\right)$ equals 0.003 , $\max \left(\left|V_{g c}-E(V)\right|\right) \quad$ equals $\quad 0.6348 . \quad \min \left(\left|V_{a c}-E(V)\right|\right) \quad$ equal $0.025 \mathrm{~s}$ and $\max \left(\left|V_{a c}-E(V)\right|\right)$ equals 2.643. This results are based on the principle of multiplication and normalization.

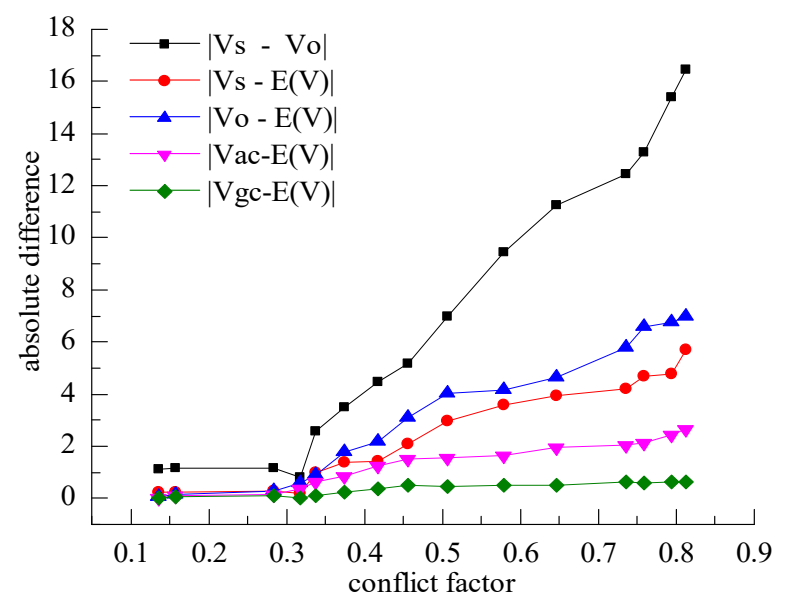

Fig. 1. The relation of absolute difference and conflict factor.

\section{Self AdAPtive Weighting Method}

To increase the calculation efficiency in the evaluation process, and obtain higher accuracy of evaluation results. We analyzed the calculation workload of the same evaluation object and system, and then, found the suite weighting method in different condition.

Analyzed the procedure of calculation case 1 and 2. The university $\mathrm{T}$ is devalued object, and scale of evaluated object is $n=1$. The number of index of evaluated system is $m=25$. And then, tracing the procedure of calculation of four weighting methods which is as subjective weighting method of AHP, objective weighting method of entropy weight and two comprehensive weighting method. Their calculation times were counted. The results are shown in Table IV.

In Table IV. Because comprehensive weighting methods of (2) and (3) based on weight vectors of subjective weighting of AHP and objective weighting of entropy weight, the calculation time is increased on the calculation times of subjective and objective weight vector. Especially the (3), its calculation time complexity is the highest, because of it involves matrix calculation and solution of linear equations.

Based on research conclusion of the 3.3 section, we discovered that if only using subjective weight of AHP or objective entropy weight cannot obtain the relatively accurate evaluation conclusion every time. But, its calculation time complexity degree is lower and easier to implement. If only use comprehensive weighting method of (3), could ensure a more accurate result, but its calculation procedure is complex and time complexity degree is higher. 
TABlE IV. Calculation Times of Four Weighting Method

\begin{tabular}{|l|l|l|l|l|}
\hline \multirow{2}{*}{\begin{tabular}{|l|l|}
\multirow{2}{*}{ Operation methods } \\
\cline { 2 - 5 }
\end{tabular}} & $\begin{array}{c}\text { Weighting method of } \\
\text { AHP }\end{array}$ & Entropy weighting & $\begin{array}{c}\text { Comprehensive weighting } \\
\text { of (2) }\end{array}$ & Comprehensive weighting of (3) \\
\hline Times of addition and reduce & 24 & 180 & 227 & 279 \\
\hline Times of multiple and division & 167 & 257 & 474 & 515 \\
\hline Basic calculation times & 167 & 257 & 474 & 515 \\
\hline
\end{tabular}

Based on the above conclusion, use the advantage of lower time complexity degree and more accurate evaluation result of weighting method of APH. In the condition that conflict factor of subjective weight and objective weight is lower. And then, combine (3) obtain the more accurate evaluation result in the condition of the bigger conflict factor, the self adaptive index weighting algorithm of index was proposed. The flow diagram of the algorithm is shown in Fig. 2.

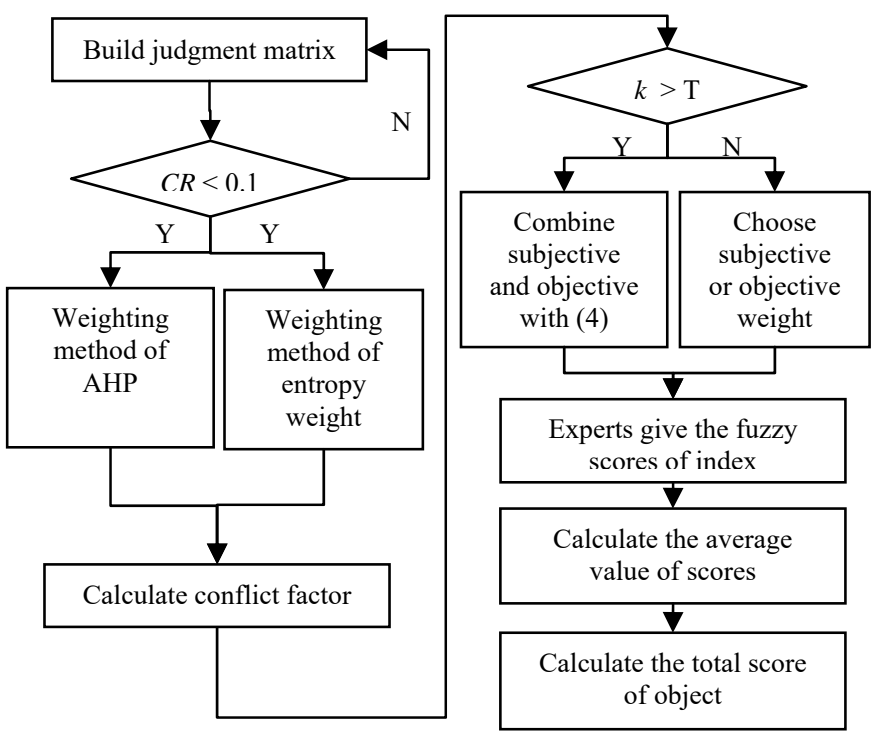

Fig. 2. The flow diagram of self adaptive weighting algorithm.

The detail steps of the algorithm are as follows.

Step1. Firstly, multi judgments build judgment matrix. If it is satisfied consistency test of index, the weighting method of AHP and entropy weighting method are used to calculate the subjective and objective weight vector $W_{s}, W_{o}$, respectively. (4).

Step2. And then, the conflict factor $\mathrm{k}$ was calculated with

Step3. If $k>T$, calculated the comprehensive weighting vector $W_{g m}$ based on game theory with (3).

Step4. If $k \leq T$, directly use the subjective weight vector or entropy weight vector, which do not need to combine

subjective and objective weight vector. So, we could reduce calculation times of combining calculation.
Step5. Finally, for every index, according to real condition, evaluation experts give score. Then, calculate the average value vector of score with (5).

Step6. Use weight vector, which is chosen by step(3) or (4), and average vector of fuzzy score by experts given to calculate the total score of the evaluated object.

To verify the adaptive algorithm is effective. And in consideration of important influence of conflict factor to final evaluation result, we continue chose calculation case 1 and case 2. Its conflict factor is between 0.284 and 0.507 , which has a certain representation. Therefore, calculation case 1 and case 2 could fully show the difference of every algorithm. Here, multiplication and division are as basic calculation. The evaluation results and calculation time are shown in Table V.

Analyzed for the results. In calculation case 1, conflict factor $\mathrm{k}=0.284$ is less than $\mathrm{T}$. According research conclusion of 3.3 section and self adaptive algorithm of this paper. Only use subjective weight vector or objective weight vector. We will be able to get into the expert scoring stage. Do not need (2) or (3) to combine subjective and objective weight vector. So that, basic calculation times is 449, which is less than comprehensive weight method based on (2) and (3). So, it reduces calculation times, and obtains the relatively accurate evaluation result.

In calculation case 2 . To obtain the comprehensive weight. The conflict factor $\mathrm{k}=0.508$ is bigger than $\mathrm{T}$. Therefore, the (3) was chose to combine the subjective and objective weighting vector $W_{g m}$. Because of the conflict factor calculation of the algorithm of this paper, the basic calculation efficiency is lower than comprehensive weighting method based on (3).

According to results analysis of calculation case 1 and case 2 , we discovered that when conflict factor $\mathrm{k}$ is less than $\mathrm{T}$, the time performance index of algorithm of this paper is better than only use comprehensive weighting of (2) or (3). And accuracy of evaluation result is not changed. When conflict factor $\mathrm{k}$ is bigger than $\mathrm{T}$, the time performance index of algorithm of this paper is not as good as the comprehensive weighting of (2) and (3). But it could obtain the same calculation result as (3).From this, the accuracy of evaluation result and calculation efficiency are balancing processed in self adaptive weighting algorithm of this paper. 
TABLE V. Calculation TImes And Evaluation Results Of Three Weighting Method

\begin{tabular}{|l|l|l|l|}
\hline \multirow{3}{*}{ Calculation Case } & \multicolumn{1}{|c|}{ Weighting method } & \multicolumn{1}{c|}{$\begin{array}{c}\text { Basic } \\
\text { calculation } \\
\text { times }\end{array}$} & Evaluation result \\
\hline \multirow{3}{*}{ Case1 } & Comprehensive weighting method of (4) & 515 & 63.40 \\
\cline { 2 - 4 } & Comprehensive weighting method of (3) & 474 & 63.12 \\
\cline { 2 - 4 } & The algorithm of this paper & 449 & 63.55 \\
\hline \multirow{3}{*}{ Case2 } & Comprehensive weighting method of (4) & 515 & 66.80 \\
\cline { 2 - 4 } & Comprehensive weighting method of (3) & 474 & 68.83 \\
\cline { 2 - 4 } & The algorithm of this paper & 532 & 66.80 \\
\hline
\end{tabular}

\section{CONCLUSIONS}

According to the analysis of calculation efficiency and results of weighting method of AHP, entropy weighting method, and comprehensive weighting method based on multiplicative normalization principle and game theory. The conclusions are as follows. When the conflict factor is less or equal 0.337 , the evaluation result is more accurate and calculation efficiency is higher based on the four weighting methods in this paper. When the conflict factor is bigger than 0.337, calculation result is more accurate based on comprehensive weighting method of game theory. But its calculation efficiency is lower than others weighting methods. Based on the result, the self adaptive weighting algorithm was proposed based on conflict threshold value. Then the calculation efficiency and accuracy of calculation result were analyzed. The analysis results show that the algorithm efficiency is higher and algorithm accuracy is more accurate in this paper.

\section{REFERENCES}

[1] P.F. Hsu, H.Y. Chiang, and C.M. Wang, "Optimal selection of international exhibition agency by using the Delphi method and AHP," Taylor \& Francis, vol. 32, pp. 1353-1369, June 2011.

[2] Y.Q. Hu, Operational Research Tutorial,Bei jing, 2007, pp. 424-426.

[3] M.X. Cheng, "Two coefficient weighting sums method for multiobjective decision making problems," Theory and Practice of System Engineering, vol. 04, pp. 23-26, April 1983.

[4] M.S. Lu. "Weight coefficient in multi-objective decision making," Theory and Practice of System Engineering, vol. 6, pp. 77-78, April 1986.

[5] Y.D. Ma and M.D. Hu, "Improved AHP method and its application in multi-objective decision making,"Theory and Practice of System Engineering,vol. 6, pp. 40-44, May 1997.

[6] J.J. Buckley, T. Feuring, and Y. Hayashi, "Fuzzy hierarchical analysis revisited," European Journal of Operational Research, vol. 129, pp. 4864, January 2001.

[7] C.C. Sun, "A performance evaluation model by integrating fuzzy AHP and fuzzy TOPSIS methods," Expert Systems with Applications, vol. 37, pp. 7745-7754, December 2010.

[8] V.Y.C. Chen, H.P. Lien, C. Liu, H., J. J.H. Liou, G.H. Tzeng, and L.S. Yang, "Fuzzy MCDM approach for selecting the best environment- watershed plan,” Applied Soft Computing,vol. 11, pp. 265-275, January 2011.

[9] G.X. Song, "Multiple attribute decision making theory and its application in mining industry", Kunming: Kunming University of Science and Technology, 2001, pp.11-25.

[10] H.M. Zhang, "Several Fuzzy Multiple Attribute Decision making Methods and Their Application", Shanghai: Shanghai University, 2013, pp. 21-32.

[11] J.I. Shieh , H.H. Wu, and H.C. Liu, "Applying a complexity-based Choquet integral to evaluate students performance," Expert Systems With Applications, vol. 36, pp. 5100-5106, March 2008.

[12] I. Kojadinovic, "Estimation of the weights of interacting criteria from the set of profiles by means of information-theoretic functional," European Journal of Operational Research, vol. 155, pp. 741-751, March 2004.

[13] J.R. Wang, K. Fan, and W.S. Wang, "Integration of fuzzy AHP and FPP with TOPSIS methodology for aero engine health assessment," Expert Systems with Applications,vol. 37, pp. 8516-8526, December 2010.

[14] M.M. Xia and Z.S. Xu, "Entropy/cross entropy-based group decision making under intuitionistic fuzzy environment," Information Fusion, vol. 13, pp. 31-47, January 2011.

[15] H.Y. Xiao and B. Xiao, "Application of meta synthesis weighting method in data fusion capability evaluation," Journal of Hunan University of Technology, vol. 22, pp. 82-85, May 2008.

[16] D. Xu, J.F. Shen, and T.M. Liu, "Research on performance testing index and method of information fusion system," Natural Science Edition of the Journal of Jiangsu University of Science and Technology, vol. 19, pp. 45-49, June 2005.

[17] Y.K. Wu, R.S. Song, and B. Chen, "Information security risk assessment based on game theory and comprehensive weighting method," Computer Engineering and Science, vol. 33, pp. 9-13, May 2011.

[18] S.J. Wang, L.J. Fei ,Y.B. Lei, and W. Tian, "Application of two comprehensive weighting methods in irrigation area evaluation," Journal of Xi'an University of Technology, vol. 25, pp. 207-211, February 2009.

[19] H.J. GAO, X. LIU, "Comprehensive evaluation method of engineering project based on fuzzy entropy weight," Modernization of Architecture Management, vol. 23, pp. 131-134, February 2009.

[20] H.L. Chen, "Research on Performance Evaluation of Asset Management", Qingdao: Shandong University of Science and Technology, 2010, pp, 1-35.

[21] S. Zhang, K. Xu, and H.T. Li, "Measurement and analysis of information dissemination in micro-blog social networks," Journal of Xi'an Jiaotong University, vol. 47, pp. 124-130, February 2013. 